\title{
LETTER REGARDING THE ARTICLE ENTITLED: 'ANATOMICAL VARIATIONS OF ANTERIOR CIRCULATION IN THE BRAINS OF PATIENTS WITH AND WITHOUT INTRACRANIAL ANEURYSM'
}

\author{
'INTRAKRANIYAL ANEVRIZMASI OLAN VE OLMAYAN HASTALARIN BEYINLERINDE ANTERIOR \\ SİRKÜLASYONUN ANATOMİK VARYASYONLARI' BAŞLIKLI YAZI İLE İLGİLİ MEKTUP
}

\author{
Halil ÖNDER \\ Yozgat State Hospital, Neurology Clinic, Yozgat, TURKEY
}

Dear Editor;

I read with great interest the article by Yllmaz et al. in which they investigate the association between the anatomical variations of anterior circulation complex and intracranial aneurysm as well as subarachnoid hemorrhage (SAH) (1). I appreciate the authors for focusing on such an interesting topic and including a considerable number of patients in the study. However, I think that there may be some critical points to be discussed for a proper understanding of the results of this report.

The potential role of arterial variations in the development of an aneurysm has been multiple times investigated previously, and there is a substantial amount of data supporting the efficient role of arterial variations in the pathophysiology of some subtypes of aneurysms (2-7). Among them, anterior cerebral artery trunk (A1) dominance has been nearly acknowledged as a potent risk factor for AcomA aneurysm formation and rupture (2-4). Generally, vessel wall shear stress, A1-A2 bifurcation angles, and flow patterns such as a single jet of blood flowing have been hypothesized as the responsible mechanisms to explain the formation of aneurysms in the AcomA artery regions, in association with ACA vascular anatomy variations (4). This consideration has also been associated with other 'termination' type aneurysms of other vascular regions (8). However, in conclusion of their analyses, Yilmaz et al. did not find a relationship between the presence of AComA aneurysm and ACA-AComA complex vascular variations. Besides, a statistical difference between
MCA aneurysm (+) and MCA aneurysm (-) patient groups could not be found in terms of MCA types as well. On the other hand, Yilmaz et al. also preferred to compare the overall patient group with cerebral aneurysm and without cerebral aneurysm (ignoring their localizations) in conclusion of which they found that MCA variations were more frequently encountered in the overall patients with cerebral aneurysm $(p=0.035)$. In addition, they concluded that variations of MCA may increase the risk of aneurysm formation and therefore have an important role in the planning of aneurysm treatment (1). A crucial point of discussion may be that, as also mentioned above, all the hypotheses to explain the association between vascular variations and cerebral aneurysms are based on the altered flow dynamics and its effects on vessel walls. Hence, for interpretation of the causal relationship, the rationale of performing comparisons between these two parameters based on their colocalizations (AComA aneurysm and ACA-AComA complex vascular variations; MCA aneurysm and MCA vascular variations) can be understood. On the other hand, I think that the increased frequency of MCA variations in the general patients with cerebral aneurysms (in all vascular localizations) cannot be interpreted as a causal connection (considering the lack of significance between the aneurysm localization and vascular variations). In my opinion, this may rather be evaluated as a coincidental connection. I also could not understand the rationale of its (presence of vascular variations) importance in the planning of aneurysm treatment?

Corresponding author: Halil Önder MD. Yozgat State Hospital, Neurology Clinic, Yozgat, TURKEY.

Telephone: +903544442066_ E-mail: halilnder@yahoo.com

Received: $20.08 .2018 \quad$ Accepted: 20.12 .2018

This article should be cited as following: Önder H. Letter regarding the article entitled: 'anatomical variations of anterior circulation in the brains of patients with and without intracranial aneurysm'. Turkish Journal of Cerebrovascular Diseases 2019; 25 (3): 184-185. doi: 10.5505/tbdhd.2018.33602 
For instance, in a distinct study, Orakdogen et al. also suggested that awareness of the cerebral vascular variations would guide choosing and applying treatment modalities, and increase the success rate in managing the patients (5). However, they based their hypothesis on their results of the significant association between the hypoplasia of A1 and AcoA aneurysms; the tendency of more frequent presence of colocalized cerebral variations in bleeding aneurysm cases according to non-bleeding aneurysm cases.

In my opinion, other than the view of direct and indirect altered blood flow effects of vascular variations, these results by Yilmaz et al. may suggest a distinct hypothesis of common structural tendency (genetic, environmental, etc.) for both vascular variations and aneurysm. Nonetheless, clarification of this view in future reports including larger number of patients is warranted, as there is no any related evidence in the literature supporting this view.

\section{REFERENCES}

1. Yılmaz A, Özkul A. Anatomical variations of anterior circulation in the brains of patients with and without intracranial aneurysm. Turkish Journal of Cerebrovascular Diseases 2018; 24: 8-13.

2. Tarulli E, Sneade M, Clarke A, Molyneux AJ, Fox AJ. Effects of circle of Willis anatomic variations on angiographic and clinical outcomes of coiled anterior communicating artery aneurysms. AJNR Am J Neuroradiol 2014; 35(8): 15511155.

3. de Rooij NK, Velthuis BK, Algra A, Rinkel GJ. Configuration of the circle of Willis, direction of flow, and shape of the aneurysm as risk factors for rupture of intracranial aneurysms. J Neurol 2009; 256(1): 45-50.

4. Castro MA, Putman CM, Sheridan MJ, Cebral JR. Hemodynamic patterns of anterior communicating artery aneurysms: a possible association with rupture. AJNR Am J Neuroradiol 2009; 30(2): 297-302.

5. Orakdogen M, Emon ST, Somay H, Engin T, Is M, Hakan T. Vascular Variations Associated with Intracranial Aneurysms. Turk Neurosurg 2017; 27(6): 853-862.

6. Kayembe KN, Sasahara M, Hazama F. Cerebral aneurysms and variations in the circle of Willis. Stroke 1984; 15(5): 846-850.

7. Nixon AM, Gunel M, Sumpio BE. The critical role of hemodynamics in the development of cerebral vascular disease. J Neurosurg 2010; 112(6): 1240-1253.

8. Valen-Sendstad K, Steinman DA. Mind the gap: impact of computational fluid dynamics solution strategy on prediction of intracranial aneurysm hemodynamics and rupture status indicators. AJNR Am J Neuroradiol 2014; 35(3): 536-543.

9. Mazighi M, Porter PJ, Rodesch G, Alvarez H, Aghakhani N, Lasjaunias P. Vascular anomalies and the risk of multiple aneurysms development and bleeding. Interv Neuroradiol 2002; 8(1): 15-20. 